\title{
Perceptions of retired professional soccer players about the provision of support services before and after retirement
}

\section{S Drawer, CW Fuller}

See end of article for authors' affiliations

Correspondence to Dr Fuller, Scarman Centre, University of Leicester, 154 Upper New Walk, Leicester LE I 7QA, UK cwf2@le.ac.uk

Accepted 23 July 2001
Objective: To determine the views of retired players about the provision of support services in English professional soccer before and after retirement and to assess the impact of career ending injury on these views.

Method: An anonymous self administered questionnaire was distributed to 500 former players registered with the English Professional Footballers' Association. The questions asked about personal details, current medical status, reasons for retirement, perceptions of the provision and quality of support services, and use of prophylactic treatments while injured.

Results: Of the 500 questionnaires distributed, 185 (37\%) were returned. The Professional Footballers' Association provided significantly $(p<0.001)$ more help and advice to retired players on medical, financial, career, and educational matters than any other organisation. Although respondents showed some satisfaction with the provision of medical support, they were significantly $(p<0.001)$ less satisfied with the provision of sports science $(23 \%)$ and education/welfare $(19 \%)$ support. Respondents who had retired through injury, however, were more dissatisfied with the provision of all services. Significantly $(p<0.001)$ more respondents agreed with the view that injuries would reduce income earning potential, contribute to medical problems, and restrict the duration of their playing career. Respondents who had been medically diagnosed with osteoarthritis were significantly more likely, at some time, to have regularly received steroid injections while injured.

Conclusion: The results presented are consistent with other evidence that the provision of injury prevention and socioeconomic services at professional soccer clubs is inadequate. The soccer industry should therefore develop a long term strategy for managing the needs of players who are forced to retire through injury.
E mployers are encouraged throughout European industry and commerce to use the process of risk assessment to control the levels and severities of work based injuries in high and low risk occupations. ${ }^{1}$ The risk of acute injury in professional soccer has been reported to be one thousand times greater than that experienced in perceived high risk industries in the United Kingdom. ${ }^{2}$ A risk assessment would therefore suggest that players require a high level of support to mitigate the medical and socioeconomic effects associated with this level of injury. In an earlier study, in which we benchmarked the levels of support services provided by professional soccer clubs in the United Kingdom, ${ }^{3}$ we found that, although the services provided for injury treatment and rehabilitation were acceptable, the resources provided for injury prevention were inadequate. Most clubs also failed to provide effective welfare support services for their players, as this aspect of support was normally an additional function undertaken by the already overburdened team physiotherapists.

The primary aim of this study was to determine the views of retired soccer players about the adequacy of the provision of medical, sports science, and socioeconomic services received during their playing careers and at the critical stage of retirement from playing soccer. The secondary aim of the study was to assess how career ending injuries affected these views.

\section{METHOD}

Implementation of the survey instrument

A questionnaire was distributed to 500 former professional players, who were registered on the Professional Footballers'
Association (PFA) database. Included with the survey was a letter from the PFA's Chief Executive explaining the purpose of the survey together with a prepaid reply envelope.

\section{Structure of the survey instrument}

The questionnaire consisted of four sections, each of which was divided into a number of subsections. The four sections requested information about personal details and medical status, retirement from playing professional soccer, perceptions of the provision and quality of club support services, and use of prophylactic treatments while injured.

\section{Personal details and current medical status}

Players were requested to provide the dates at which each of the following events occurred: birth, first professional contract, retirement from professional soccer, and, if relevant, when they had been medically diagnosed with osteoarthritis (OA) in any of the lower limb joints. Details were also requested on the highest playing level achieved.

\section{Retirement from playing professional soccer}

Players were requested to identify the major reason for their retirement from playing professional soccer and the organisations that had provided them, if required, with medical, financial, career, or educational advice. Details were also requested

Abbreviations: PFA, Professional Footballers' Association; OA, osteoarthritis 
on the occupations undertaken since retirement, which were categorised using the Social Trends method of classification. ${ }^{4}$

\section{Perceptions of the provision and quality of support services}

Players were asked to indicate their level of satisfaction with the medical, sports science, and welfare/education services provided by their former clubs during their playing career, using the categories "very satisfied", "satisfied", "neither satisfied nor dissatisfied", "dissatisfied", and "very dissatisfied". They were also asked to express their views on a list of statements that assessed their perceptions of the influence that injury had or was likely to have on the career of a professional soccer player using categories of "strongly agree", "agree", "neither agree nor disagree", "disagree", and "strongly disagree". These statements covered individual and team performances, length of playing career, medical problems, earning potential, and future career options.

\section{Use of prophylactic treatments while injured}

Players were asked to indicate the types (supports/strappings, modalities, medication, and steroid and non-steroid injections) and frequencies (never; rarely (once or twice in career); occasionally (once or twice a season); frequently (three to five times a season); regularly (more than five times a season) of medical assistance provided by their clubs to assist them to play or train while injured.

\section{Statistical analysis}

Values are reported, where appropriate, as mean (SD) (range). All statistical analyses were carried out using the Statistical Package for the Social Sciences (SPSS version 9.0.) for Windows computer package. Results were treated as categorical data and were assessed using cross tabulation methods with exact $\chi^{2}$ for one and two samples, and statistical significance was accepted at the $\mathrm{p}<0.05$ level, unless stated otherwise.

\section{RESULTS}

Of the 500 questionnaires distributed to former professional soccer players, 185 (37\%) were returned.

\section{Personal details and current medical status}

The mean age of the respondents was 47.6 (13.2) (20-84) years, the mean age at which they signed their first professional contract was $18.2(2.4)(16-27)$ years, and the mean age at which they retired from playing professional soccer was 32.5 (5.2) (17-42) years. Of all the respondents, 60 $(32 \%)$ reported that they had been medically diagnosed with $\mathrm{OA}$ in at least one of the lower limb joints.

\section{Retirement from playing professional soccer}

There were no significant differences in the major reasons given by players for retiring from competitive soccer (acute injury, 33 (19\%); chronic injury, 46 (27\%); new career, 32 (19\%); non-renewal of contract, 30 (18\%); other, $30(18 \%))$. There was a significant difference between the reason given for retirement and the OA status of respondents (OA: acute, 15 (25\%); chronic, 21 (36\%); other, 23 (39\%); non-OA: acute, 15 (14\%); chronic, 20 (19\%); other, $69(66 \%)$; $p<0.001)$. On average, respondents had been employed since retirement in 2.1 (1.0) occupations, which lasted 7.0 (7.3) years per occupation. Of these occupations, $86 \%$ had been full time, and $14 \%$ had been part time positions. There were significant differences $(p<0.001)$ in the proportions of respondents entering each occupation after retirement (fig l). A very high proportion of players had at some time taken up coaching and/or management positions within professional soccer, whereas others took up sales positions within their own enterprise or for an employer (associate professional/technical, 125 (77\%);

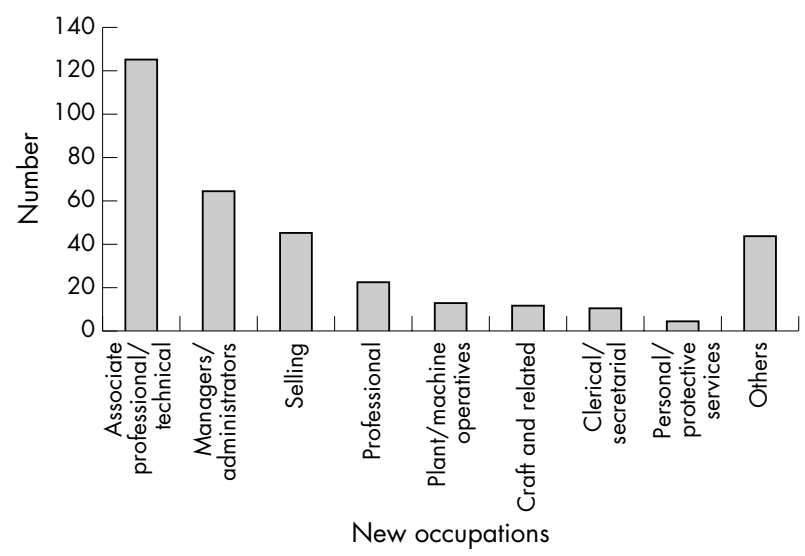

Figure 1 Major occupations taken up by retired professional soccer players.

team manager/administrator, 64 (39\%); sales, 44 (27\%); other, $47(29 \%))$. Under the category "other", after dinner speaking, driving instruction, taxiing, and youth work predominated.

Table 1 shows the proportions of respondents who received assistance after retirement with medical, financial, career, and educational needs, together with the service providers. The organisations classified as "others" were primarily educational establishments, where former players had progressed into lecturing or educational occupations. The PFA provided significantly $(p<0.001)$ more help to former players than any other organisation on medical, financial, career, and educational matters.

\section{Players' perceptions of the adequacy of support services provided before retirement}

There were significant differences $(p<0.001)$ in the players' levels of satisfaction/dissatisfaction with the medical, sports science, and education/welfare services provided during their playing careers (fig 2). Almost two thirds (63\%; 114) of respondents expressed satisfaction with the medical support provided, but the levels of satisfaction with sports science (40: $23 \%)$ and education/welfare (32: 19\%) support were significantly lower.

There were no significant differences in the respondents' perceptions of the provision of medical, sports science, and welfare/education services as a function of whether the players had been medically diagnosed with OA. However, when responses were categorised according to the players' reasons for retirement, there were significant differences $(p<0.001)$ in the levels of satisfaction expressed for the provision of medical services (fig 3).

A larger proportion of respondents expressed dissatisfaction with medical service provisions if they had retired because of either acute (15: 45\%) or chronic (16:35\%) injury compared with those who had retired for other reasons (12: $13 \%)$. The levels of dissatisfaction were even greater for the provision of sports science support services (acute injury, 21 (63\%); chronic injury, 26 (56\%); other, 34 (37\%)) (fig 4) and education/welfare services (acute injury, 28 (85\%); chronic injury, 29 (64\%); other, 48 (53\%)) (fig 5), but, in both cases, the differences were not significant.

\section{Players' perceptions of the impact of injury on their} careers

There were significant differences in the opinions expressed by respondents concerning the impact of injury on their careers (fig 6). More respondents agreed than disagreed with the statements that injuries obtained while playing professional soccer would reduce income earning potential (86: 49\%; $\mathrm{p}<0.001$ ), contribute to medical problems (158: 89\%; 
Table 1 Proportions of retired professional soccer players receiving assistance from organisations after retirement

\begin{tabular}{lllll}
\hline & \multicolumn{4}{l}{ Proportion of respondents receiving help (\%) } \\
\cline { 2 - 5 } Organisation & $\begin{array}{l}\text { Medical } \\
\text { problems }\end{array}$ & Financial aid & $\begin{array}{l}\text { Career } \\
\text { advice }\end{array}$ & $\begin{array}{l}\text { Educational } \\
\text { needs }\end{array}$ \\
\hline Football Association & 5 & 7 & 10 & 12 \\
Professional Footballers' Association & 34 & 49 & 41 & 46 \\
Football/Premier Leagues & 2 & 9 & 3 & 3 \\
Former club & 14 & 9 & 6 & 4 \\
Club insurance & 9 & 6 & $<1$ & $<1$ \\
Personal insurance & 14 & 17 & 1 & $<1$ \\
Fellow players & 17 & 9 & 26 & 14 \\
Others & 1 & $<1$ & 3 & 2 \\
\hline
\end{tabular}

\section{$\square$ Very satisfied}

$\square$ Neither satisfied nor dissatisfied $\square$ Dissatisfied

- Very dissatisfied

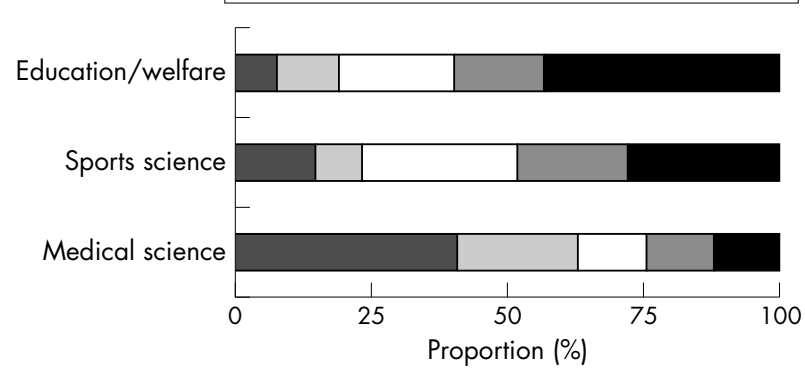

Figure 2 Players' levels of satisfaction with the support services provided during their professional playing careers.

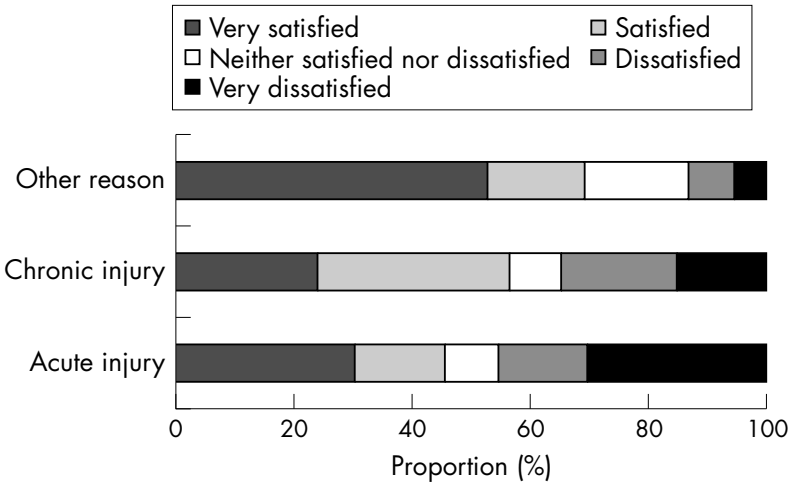

Figure 3 Players' satisfaction with the medical support services provided as a function of their reasons for retirement.

$\mathrm{p}<0.001)$, restrict the duration of their playing career $(125$ : $71 \% ; \mathrm{p}<0.001$ ), affect their own performance (130: 73\%; $\mathrm{p}<0.001$ ), and affect their team's performance (143: 81\%; $\mathrm{p}<0.001$ ). There were significantly greater differences in the perceptions of respondents, who had been diagnosed with OA, compared with those respondents who had not, about the effect of injury on the duration of their playing career, long term medical problems, and future earning potential.

There were significant differences between respondents' perceptions of whether a soccer injury may affect their playing and non-playing careers as a function of their reasons for retirement. Players who had retired through acute or chronic injury were more likely to agree that soccer injuries would limit the duration of their football career (acute injury, 29 (88\%); chronic injury, 38 (84\%); other, 55 (63\%); $p<0.01)$, lead to long term injury problems (acute injury, 31 (94\%); chronic injury, 43 (96\%); other, 75 (82\%); p<0.01), limit their future

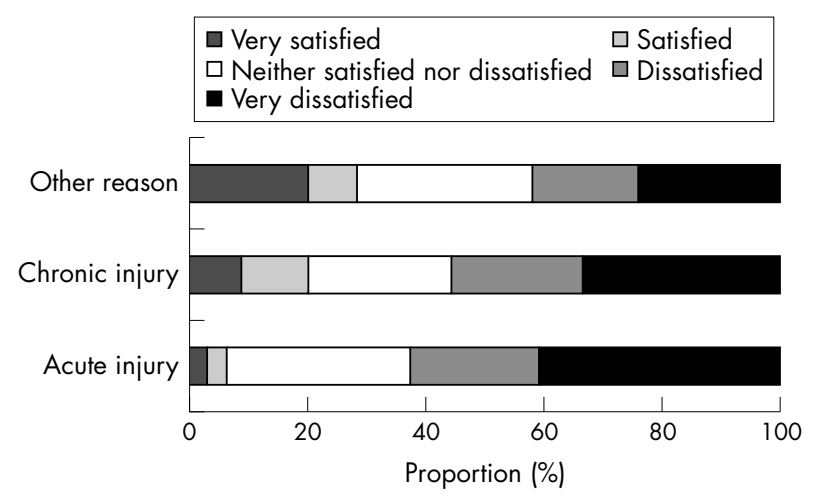

Figure 4 Players' levels of satisfaction with the sports science support services provided as a function of their reasons for retirement.

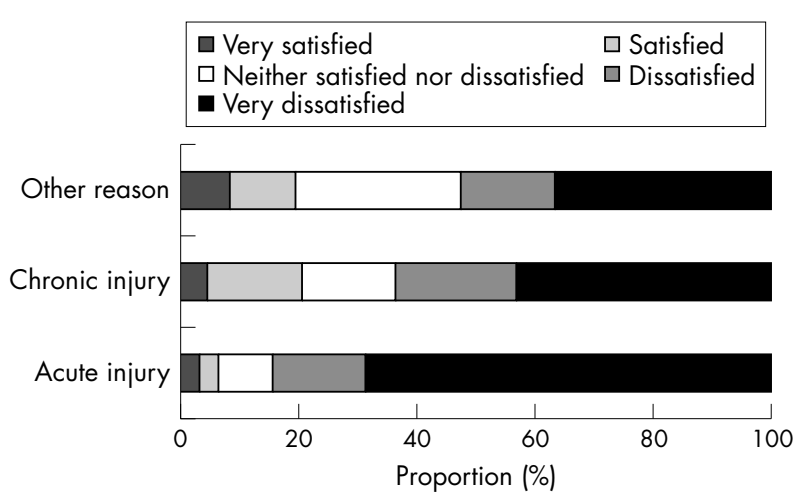

Figure 5 Players' levels of satisfaction with the educational/ welfare support services provided as a function of their reasons for retirement.

earning potential (acute injury, 22 (67\%); chronic injury, 27 $(61 \%)$; other, $34(37 \%) ; p<0.01)$, limit their future career opportunities (acute injury, 23 (70\%); chronic injury, 25 (56\%); other, 39 (43\%); $<<0.001)$, and affect their individual playing performance (acute injury, 28 (85\%); chronic injury, 34 (76\%); other, $63(70 \%)$; $\mathrm{p}<0.05)$.

\section{Use of prophylactic treatments while injured}

Figures 7 and 8 show the types and frequencies of medical support used by players when injured in order to train and play respectively. Most players used supports/strappings (competition, 64\%; training, 58\%), modalities (competition, 59\%; training, 59\%), and medication (competition, 53\%; training, $47 \%$ ) at least once a season. However, significantly fewer respondents had used non-steroid (training, 21 (12\%) 


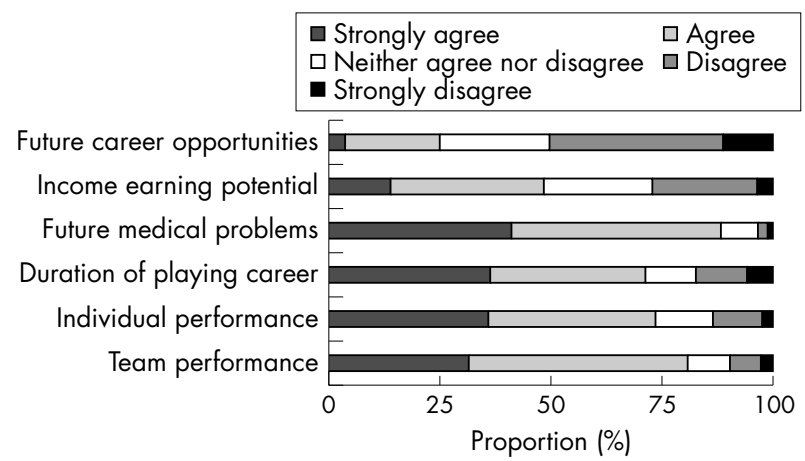

Figure 6 Players' perceptions of the impact of injury on their careers.

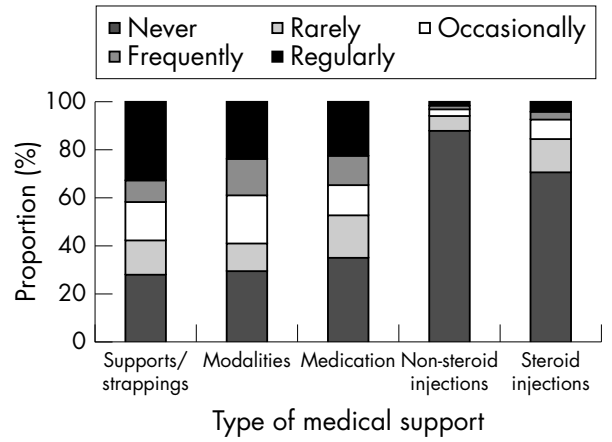

Figure 7 Type and frequency of medical support received while injured, during training sessions. Definitions: rarely, once or twice in career; occasionally, once or twice a season; frequently, three to five times a season; regularly, more than five times a season.

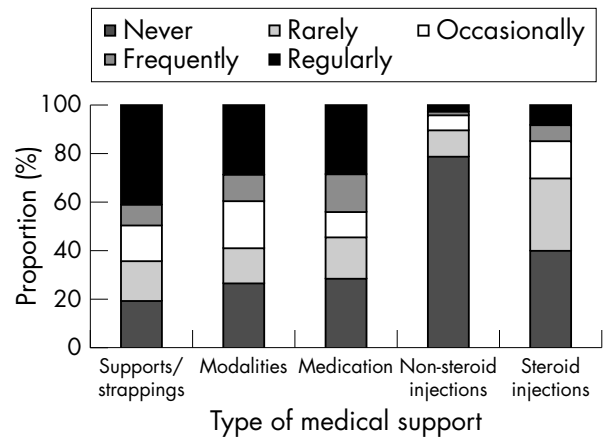

Figure 8 Type and frequency of medical support received while injured, during competition. Definitions: rarely, once or twice in career; occasionally, once or twice a season; frequently, three to five times a season; regularly, more than five times a season.

$(\mathrm{p}<0.001)$; competition, $37(21 \%)(\mathrm{p}<0.001))$ and steroid (training, 52 (29\%) $(\mathrm{p}<0.001)$; competition, $100 \quad(56 \%)$ $(p<0.001))$ injections in order to train or play while injured.

Of the respondents who had been medically diagnosed with $\mathrm{OA}$, a significantly greater proportion indicated that they had at some time regularly (more than five times a season) received steroid injections in order to play in competitive matches (never: OA, 19 (32\%); non-OA, 53 (49\%); rarely: OA, 18 (30\%); non-OA, 31 (28\%); occasionally: OA, 8 (13\%); nonOA, 16 (15\%); frequently: OA, 6 (10\%); non-OA, 5 (5\%); regularly: OA, 9 (15\%); non-OA, $4(4 \%)$ ) (fig 9), and there was a non-significant trend indicating that respondents had also regularly had steroid injections in order to train (never: OA, 39 (65\%); non-OA, 78 (72\%); rarely: OA, 7 (12\%); non-OA, 18 (17\%); occasionally: OA, 6 (10\%); non-OA, 8 (7\%); frequently:

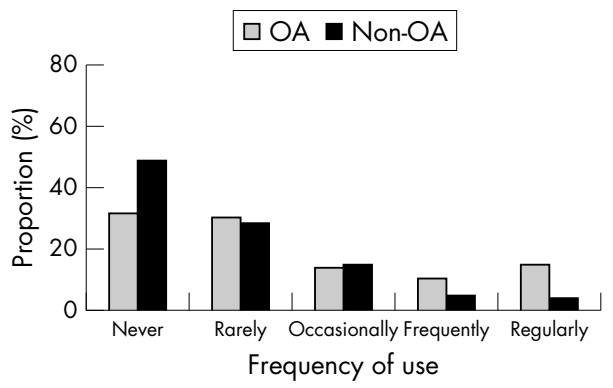

Figure 9 Use of steroid injections during competition, while injured, as a function of diagnosed osteoarthritis $(\mathrm{OA})$ status. Definitions: rarely, once or twice in career; occasionally, once or twice a season; frequently, three to five times a season; regularly, more than five times a season.

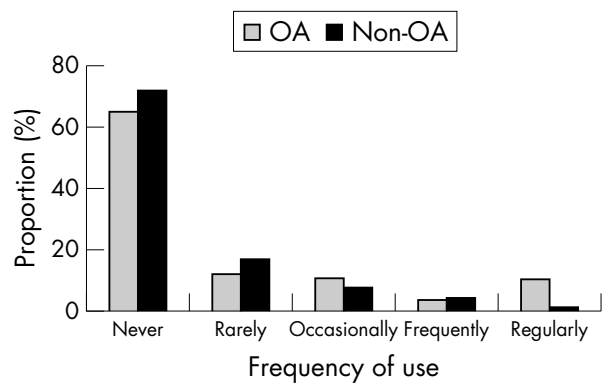

Figure 10 Use of steroid injections during training, while injured, as a function of diagnosed osteoarthritis (OA) status. Definitions: rarely, once or twice in career; occasionally, once or twice a season; frequently, three to five times a season; regularly, more than five times a season.

OA, 2 (3\%); non-OA, 4 (4\%); regularly: OA, 6 (10\%); non-OA, 1 (1\%)) (fig 10).

\section{DISCUSSION}

The response rate $(37 \%)$ for the survey was comparable to those obtained from earlier postal surveys with English soccer clubs involving physiotherapists ${ }^{3}(40 \%)$, players ${ }^{5}(38 \%)$, and safety officers ${ }^{6}(40 \%)$. It was also comparable to employee response rates for postal surveys in other small and medium sized business studies. ${ }^{7}$

Some important points have been highlighted about the employment and practices of physiotherapists and club doctors in professional soccer clubs. ${ }^{89}$ Although the Football and Premier Leagues ${ }^{10}$ have now introduced guidelines and requirements for the recruitment of medical staff working in professional soccer clubs, many of the problems raised still remain to be resolved. Although it is possible that some respondents were unaware of what constituted good medical practice, this study has shown that most players (63\%) were satisfied with the medical support provided during their soccer careers. However, a significant proportion of respondents did indicate a level of dissatisfaction (24\%), and this supported previous reports of the diversity of experience, qualifications, and practices of medical staff found in professional soccer clubs. ${ }^{389}$ A higher proportion of respondents who had retired because of injury indicated dissatisfaction with the medical service provision than those who had retired for other reasons (acute, 45\%; chronic, 35\%; other, $13 \%)$. Although more players retired through chronic $(27 \%)$ than acute (19\%) injury, it appeared that a one off traumatic injury, rather than a series of minor injuries leading to chronic injury, evoked the greater concern among players.

There is evidence of a culture within professional soccer in the United Kingdom that leads players to train and play while not fully fit, ${ }^{8}$ and this exposes them to a high risk of 
reinjury. ${ }^{11}{ }^{12}$ Unfortunately, players are often under pressure to play for personal reasons or as a result of pressure from their club's management and/or medical team. Because damage to soft tissues has been identified as a high risk factor in the development of joint $\mathrm{OA},{ }^{13}$ respondents were asked to indicate the frequency and level of medical support they had received from their clubs in order to assist them to play and/or train while injured. Respondents identified that supports/ strappings, modalities, and medication were commonly used by players while injured, and these results are consistent with other data indicating that playing while injured has been accepted practice in UK professional soccer. ${ }^{8}$ The use of steroid injections by players at some stage of their career was found to be greater for competition (57\%) than for training (29\%). Turner et al ${ }^{14}$ have reported a similar level of steroid use (59\%) by soccer players. The results showed that respondents who had regularly been provided with steroid injections in order to play while injured were more likely to be diagnosed with OA. Although the numbers of respondents who had regularly used steroid injections were small (competition, 13; training, 7), the results provide an indication of the long term risks associated with receiving steroid injections on a regular basis. The level of use of non-steroid injections, although lower than that for steroid injections, was also greater for competition $(21 \%)$ than for training $(12 \%)$.

Before and at retirement, whether planned or unplanned, players face many decisions about medical, financial, educational, and career matters. This study shows that the PFA was by far the largest provider of advice and aid to players at this stage of their careers (medical, 34\%; financial, $49 \%$; career, $41 \%$; education, $46 \%$ ). This is significant because the PFA have only established most of their player benefit projects, such as the non-contributory cash benefit scheme, the contributory pension scheme, and the management of players' contracts, pensions, and mortgages, in the last 20 years. ${ }^{15}$ Many of the respondents in the survey may therefore have retired before these services were available. Fellow professionals, rather than former clubs, were also a significant source of support for many retired players, especially with regard to the provision of advice on future careers. The Premier and Football Leagues and players' former clubs only provided support of any type in a small number of cases. Personal insurance policies were used by a limited number of players to provide medical (14\%) and financial $(17 \%)$ support after retirement. This reflects the overall low level of advice received by players during their playing careers about their potential needs after retirement.

A significant proportion of players remained, at least for a period of time, within the soccer industry after retirement, as a coach, scout, or manager at youth, reserve, or first team level. However, there are only a limited number of long term employment opportunities in professional football, and these cannot cater for the large number of players who wish to remain in the game. For the elite players, high profile employment through, for example, media work was a significant option but, for other players, moving into self employment through the retail, taxi, security, construction, and cleaning business sectors was more common. Long term career opportunities are an area of concern for many retired players because most are restricted in their options through lack of formal education, although the PFA does provide financial support to retired players in order to address this issue. The problem has also been partly resolved for younger players by the new football academies, which have been established at some Premier and Football League clubs as part of the Football Association's "Charter for Quality" initiative. ${ }^{16}$ Youth players at these academies receive educational guidance, in addition to the development of their soccer skills, in order to prepare them for a career outside professional soccer. However, in the interim period, many older players still face the same predicament of limited employment opportunities when they retire.

Only $25 \%$ of respondents felt that injury would influence their future career opportunities. Although this figure is

\section{Take home message}

The provision of injury prevention and socioeconomic support services by English professional soccer clubs is inadequate compared with the levels of acute and chronic injuries suffered by players. The soccer industry should develop a long term strategy for managing the needs of players who are forced to retire through injury.

higher than the $16 \%$ reported by Turner et al, ${ }^{14}$ both of these values are surprisingly low considering the players' perceptions that injury affected future medical problems (89\%) and duration of the playing career $(71 \%)$. This may be because most respondents had remained, at least for a time, within professional soccer through scouting, coaching, and management positions. The reason for retirement was a factor that significantly differentiated between respondents' opinions on the influence that injury may have on a player's socioeconomic status and playing performance. In most cases, more respondents who retired because of acute or chronic injury agreed with the statements that injury would limit the duration of their playing career and lead to long term medical problems. This study also shows that respondents who had been diagnosed with OA in at least one of the lower limb joints had greater concerns about the impact of injury on the duration of their playing career, long term medical problems, and future earning potential than players who had not been diagnosed with OA.

The provision of sports science and education/welfare services is relatively new in English soccer, ${ }^{3}$ and this was reflected by the low level of satisfaction expressed by the respondents for these services (sports science, 23\%; education/welfare, $19 \%)$. At present, welfare and general support is provided at many clubs by the physiotherapist, ${ }^{2}$ who may understand the concerns of the players but who has little time available to provide this advice alongside the other services they provide. In addition, physiotherapists are untrained to carry out such a role.

\section{Conclusions}

The inadequacies identified in the provision of injury prevention support services at UK professional soccer clubs ${ }^{3}$ have been supported by the views expressed by retired professional soccer players in this survey. This has important implications for the UK professional soccer industry because health and safety legislation requires employers to identify hazards and risks arising from their work activities and to provide appropriate information and training about the risks. ${ }^{17}$ At present, players are inadequately informed about the health risks arising from a career in professional soccer and the control measures available to reduce these risks. ${ }^{5}$ While the levels of chronic injury remain high among retired players, the ruling bodies in soccer will remain vulnerable until health surveillance among professional soccer players has been adequately addressed. ${ }^{18}$ Without a strategy for providing adequate long term assistance for players forced to retire through injury, the soccer industry remains open to the possibility of litigation from players seeking financial redress for loss of income.

\section{ACKNOWLEDGEMENTS}

We would like to acknowledge the invaluable assistance provided by the Professional Footballers Association, in particular the help provided by George Berry and Lindsay Gallagher in administration of the players' database. SD acknowledges financial support from Loughborough University while undertaking part of the work described here. 


\section{Authors' affiliations}

S Drawer, UK Sports Institute, 40 Bernard Street, London WCIN 1ST, UK

CW Fuller, Scarman Centre, University of Leicester, 154 Upper New Walk, Leicester, Leicestershire LE1 7QA, UK

\section{REFERENCES}

1 European Commission. Guidance on risk assessment at work. Luxembourg: Office for Official Publications of the European Communities, 1996.

2 Fuller CW. The role of risk management in reducing players' injuries in professional football. In: Murphy P ed. Singer \& Friedlander's review 1999-2000 season. London: Singer \& Friedlander, 2000:55-8.

3 Drawer S, Fuller CW. Benchmarking the levels of injury support services available at English professional football clubs. European Journal for Sport Management 1999;6:34-47.

4 HMSO. Social trends. London: HMSO, 2000.

5 Hawkins RD, Fuller CW. A preliminary assessment of professional footballers' awareness of injury prevention strategies. Br J Sports Med 1998:32:140-3

6 Fuller CW, Hawkins RD Assessment of football grounds for player safety. Safety Science 1997;27:115-28.

7 Storey DJ. Understanding the small business sector. London: Routledge, 1994

8 Roderick M, Waddington I, Parker G. Playing hurt; managing injuries in English professional football. International Review for the Sociology of Sport 2000;35: 165-80.

9 Waddington I, Roderick M, Naik R. Methods of appointment of club doctors and physiotherapists in English professional football clubs: some problems and issues. Br J Sports Med 2001;35:48-53.

10 Premier League. The FA Premier League handbook, season 1998-99. London: The Football Association Premier League Limited, 1998.

11 Ekstrand J, Gillquist J. Soccer injuries and their mechanisms: a prospective study. Med Sci Sports Exerc 1983;15:267-70.

12 Hawkins RD, Fuller C. A prospective epidemiological study of injuries in four English professional football clubs. Br J Sports Med 1999;33:196-203

13 Roos H. Are there long-term sequelae from soccer? In: Mandelbaum BR, Garrett WE, Kirkendall DT, eds. Clinics in sports medicine: soccer injuries. Philadelphia: WB Saunders Company, 1998:819-34.

14 Turner AP, Barlow JH, Heathcote-Elliott C. Long term health impact of playing professional football in the United Kingdom. Br J Sports Med 2000;34:332-7.

15 Professional Footballers' Association. http://www.thepfa.co.uk.

16 Wilkinson H. Football education for young players: 'a charter for quality'. London: The Football Association, 1997.

17 Fuller CW. Implications of health and safety legislation for the professional sportsperson. Br J Sports Med 1995;29:5-9.

18 Fuller CW, Hawkins RD. Developing a health surveillance strategy for professional football in compliance with UK health and safety legislation. BrJ Sports Med 1997;31:148-52.

\section{COMMENTARY}

This paper raises a number of interesting matters. However, it is important to be clear about what the paper does not do. In particular, it does not document the quality of provision of support services available to soccer players; rather it documents players' perceptions of the quality of provision. These, of course, are not the same thing. Different groups are likely to have different criteria for assessing quality of provision, and it is quite possible that players may be satisfied with services that an independent expert may consider unsatisfactory.

This is particularly relevant to the authors' finding that $63 \%$ of ex-players expressed satisfaction with the provision of medical services during their playing careers. What does this indicate? Is it an indication of high quality services or that players in the recent past had (perhaps still have) low expectations? The authors note that "it is possible that some respondents were unaware of what constituted good medical practice" and this may be important to bear in mind when considering their findings.

In this context, a recent study in the journal was critical of the qualifications and experience of club doctors and physiotherapists in English soccer clubs, and their manner of appointment was described as "a catalogue of poor employment practice". ${ }^{1}$ As all the respondents in the current study were ex-players, their experiences will relate to an earlier period in which the situation in relation to the employment of club doctors and physiotherapists was almost certainly worse than that documented in the study by Waddington et al. In this context, it may be that the relatively high level of satisfaction of the ex-players with medical services in this study is primarily a reflection of their general lack of awareness of what constitutes good quality care.

A further significant finding of this paper concerns the fact that the players' trade union, the PFA, provided significantly more help to ex-players, in terms of medical, financial, career, and educational support, than did any other organisation. While this reflects credit on the PFA, it raises important points about the legal (and moral) responsibilities of the former employers (the clubs) and organisations such as the Football Association and Football League. A final related point is that the authors refer to the vulnerability of the "soccer industry" to litigation from players seeking financial redress for injuries and other matters. It would be helpful to pinpoint those organisations within the "soccer industry" with whom such legal and moral responsibility primarily lies.

I Waddington

Director, Centre for Research into Sport and Society, University of Leicester, iw11@leicester.ac.uk

\section{REFERENCE}

1 Waddington I, Roderick M, Naik R. Methods of appointment of club doctors and physiotherapists in English professional football clubs: some problems and issues. Br J Sports Med 2001:35:48-53. 